\title{
Environmental policy under some asymmetric social-economical factors
}

\author{
Chien-Chieh Huang ${ }^{1}$, Huei-Chin Lin $^{2}$ \\ ${ }^{1}$ Soochow University, Taipei, Taiwan \\ ${ }^{2}$ National Dong Hwa University, Hualien, Taiwan \\ Email address: \\ cxh213@scu.edu.tw (Chien-Chieh Huang), hclin@mail.ndhu.edu.tw (Huei-Chin Lin)
}

To cite this article:

Chien-Chieh Huang, Huei-Chin Lin. Environmental Policy under Some Asymmetric Social-Economical Factors. International Journal of Economics, Finance and Management Sciences. Vol. 1, No. 1, 2013, pp. 38-42. doi: 10.11648/j.ijefm.20130101.15

\begin{abstract}
We consider situations where some social-economical factors, such as environmental awareness and other factors promoting greener environment, not only affects market demand and output, but also affects firm's green innovative tendencies. This paper shows that if these social-economical factors are strong enough to move the market demand toward environmental friendliness, firm's strategies might shift toward greener technology or environmental friendlier practices. If these effects on demand for greener environment are large enough, stringent environmental policy would induce more firms to produce more.
\end{abstract}

Keywords: Stringent Environmental Policy, Environmental Awareness, Demand Effect, Induced Output Effect

\section{Introduction}

It is often claimed that stricter environmental standard usually makes production unprofitable and forces firms out of business. However, M. E. Porter [17] and M. E. Porter and C. van der Linde [18][19] have argued that stringent environmental standard has dynamic benefits derived from its effect on promoting innovation. The dynamic benefits might be derived from the increased market share when most governments are forced to tighten up their environmental regulation, and the firm has a cheaper abatement technology due to its investment on abatement innovation ahead of its competitors. The dynamic benefit might come from demand side when consumers are willing to pay more for greener or less pollutional products and when they start buying more organic or environmental friendly goods. This demand side pressure had been much more prevalent in Europe in the past decade and has since been spreading throughout the world. In Europe, greener and cleaner production was a common goal for many governments as well as most European firms and their trading partners. And this kind of demand side pressure came from the consumers' environmental awareness which made them willing to pay more and to ask for greener and cleaner products. Actually, in European countries as well as in many other countries, the government's green policy was forced by the consumer's pressure or the "green"political parties. For example,
Germany's green party never wins the majority of votes, but it helped Germany to adopt many aggressively greener policies than other European countries. One German politician said that there's no turning back now, once they were on their way to be green, although he and most of the government officials were never the advocates of green policies. We can also find that many government officials did not really know what the best policy for their country should be, either green or brown. They simply chose a policy and then kept the policy going.

The pressure for cleaner production process is augmenting unceasingly, whilst in or out of the regulated sector, the industry has to adapt itself to a better abatement technology in order to meet the challenge. According to the literature about firms'incentive for environmental innovation, most studies argue that only larger corporations may adopt environmental R\&D strategies. Dean, Brown and Stango [4] examine new business formations across 170 manufacturing industries over a 10 year span (from 1977 to 1987) and argue that stringent environmental regulation may discourage small business formations, because small and medium enterprises (SMEs) face higher unit pollution abatement costs and unequal treatment from regulatory authorities. Nevertheless, G. Noci and R. Verganti [15] analyze four selected case studies to show that environmental innovation may occur and may also have strategic implications in SMEs.

Actually, many R\&D investments might not get the 
much awaited results of success. Some $R \& D$ may take a long time toward fruition. Nevertheless, there are many less costly innovative ideas. Creativity may take much less investment than we think. Most Taiwanese companies were smaller than the firms in the SMEs categories, but they were quite diligent and creative, when they were competing in the world market. They did not have enough budgets to invest on green technology, but they were required to comply with the European environmental standards when they were trading with European companies. However, even without enough budgets to innovate, Taiwanese companies were gaining a lot of orders from European markets in the last two decades, while beating their American and Japanese competitors, not by cheating, but by complying with much more stringent European environmental standards.

The size of the firm may or may not be important in studying the issue of environmental R\&D incentives. And the innovation investment may not always get results. But what we really care about is the effect of regulation on environmental $R \& D$ incentives, not the amount of investment the firm actually spends on R\&D projects, because small investment might be creative enough to get a better abatement results than a much larger investment. Whether those smaller companies are benefited from behavior advantages over their larger counterparts (e.g. flexibility in response to external threat or opportunity, efficient internal communication, or interactive management style), or by other means, they are successful in conforming to tougher standards with cheaper costs. The ability to adapt in response to a tougher standard is usually different across regions or across different groups of firm with different realized competitive strategies or positioning (see D. Keeble[8]; and L. A. Lefebvre and E. Lefebvre [10]). Some acquire the innovation knowledge by the factor of organizational or geographic proximity (see S. Davenport [3]), some by their government's interventions or other forces to promote collaboration amongst SMEs for improving innovation capacity by increasing social capital or learning ability through networking or through local clusters (see P. Cooke and D. Wills [2]; K. Hoffmana, M. Parejoa, J. Bessant, and L. Perrena[7]; andL. K. Mytelka [14]). It would be interesting to know how this capacity to adapt affect firm's output strategy and whether environmental policies has some positive effect in addition to this adapting capabilities.

Jean-Jacques Laffont and Jean Tirole[9] argue that market based instruments are incapable of properly dealing with innovation, because of inefficiencies in pollution permit markets and government's arbitrary policy interventions. Denicolo [5] shows that if the government may pre-commit, effluent taxes give a higher incentive for firms to invest in $\mathrm{R} \& \mathrm{D}$ than permits when post-innovation output level is sufficiently high.However, if the government can adjust the level of taxes and permits after the innovation has occurred, taxes and permits are fully equivalent. Montero [12] investigates the incentive to invest in new abatement technologies under different regulatory instruments.
He argues that, with induced output effect derived from lower abatement costs, command-and-control instruments can generate stronger incentives to innovate than market-based instruments.Mohr[11] derives results consistent with "Porter's hypothesis"in a general equilibrium framework.However, he shows that a policy conforming to "Porter's hypothesis" results may not be optimal. By allowing free-riding and firm's inability to coordinate, Far$\operatorname{zin}[10](2003)$ shows the condition under which a stricter standards increases the number of firms in the industry, raises the industry output, and reduces long-term total pollution.

Our main purpose here is to study the factors, such as environmental awareness or some other social-economical or industrial structures, that put the pressure on market demand, such demand effect might push firms toward greener technology without sacrificing their output or competitiveness. Our model differs from Montero [12], Mohr [11], and Farzin[6], in the sense that we consider not only the output and demand effect, but also incorporate the social-economical factor into our model. We check the effect on firm's decision when market demand toward environmental friendly practices is increasing.If the demand effect is large enough, stringent government policy may increase not only the optimal output level but also the number of firms in the industry. We also investigate the factors which have some influences on firms' R\&D strategies, and found that without the positive "induced output effect", the direct effect of cost saving in new abatement technology may not be large enough to warrant R\&D investment.

\section{The Model}

Consider a Cournot industry with $\mathrm{n}$ identical profit-maximizing firms that produce a homogeneous good which generates pollution. Each firm produces $y_{i}, \mathrm{i}=1,2, \ldots, \mathrm{n}$, with a production cost $\mathrm{C}\left(y_{i}\right)$, with $\mathrm{C}^{\prime}>0$ and $\mathrm{C}^{\prime \prime} \geq 0$. Total output in the industry is $\mathrm{Y}=n y_{i}$. Let $(1-\alpha) y_{i}$ denote the firm's final emission after abatement, and $\alpha$ is the mandatory abatement level. When there is no regulation on emission, total emission is equal to Y. With mandatory emission standard (that is, abatement level is set to $\alpha$ ), firm's abatement costs is $\theta_{\mathrm{i}} \alpha y_{i}$, where $\theta$ is the abatement cost per unit of emission. Firm can improve its abatement performances by investing in new abatement technology. Firm invests $K_{i}$ to reduce the abatement costs, and the $R \& D$ production function is $\theta_{\mathrm{i}}=f\left(K_{i}\right)$, with $f(0)=1, f(\infty)>0, f^{\prime}<0, f^{\prime \prime}>0$, and $f^{\prime \prime \prime} \leq 0$. The cost of environmental $\mathrm{R} \& \mathrm{D}$ is $v_{i} K_{i}$. Since environmental innovation takes time to develop and be effective, the R\&D decision (a rather long-term project in essence) is made much earlier and less frequent than the output decision (a short-term decision compared to the R\&D decision). The optimal amount of $K_{i}$ is determined by maximizing $\pi_{\mathrm{i}}\left(K_{i}\right)-v_{i} K_{i}$, where $\pi_{\mathrm{i}}\left(K_{i}\right)$ is firm i's (subgameperfect) Nash equilibrium profit. So the optimal amount of $K_{i}$ must satisfy $\mathrm{d} \pi_{\mathrm{i}}\left(K_{i}\right) / \mathrm{d} K_{i}=v_{i}$. And when the optimal investment is chosen, the abatement technology is fixed to $\theta$. 
We can setup a three stage game: in the first stage government choose the mandatory environmental standard, while in the second stage, firm chooses its R\&D investment $\mathrm{K}$. And in the final stage, firm chooses its optimal output level. However, government may or may not know the "best" policy to adopt. Even if the government official knows what the best policy is, there are uncertainty in politics and practical difficulties for the well-informed official to implement the policy. So most governments just choose a mandatory standard not according to economic efficiency or Pareto optimality criterion, but by negotiating and logrolling between different political parties.

It is less political but not less complicated in the R\&D investment case. For any investment in a environmental $\mathrm{R} \& \mathrm{D}$ project, there is the uncertainty about the probability of fruition, and the uncertainty about the timing of fruition. When government set a stringent standard, firm has to conform no matter what and no matter how. The more stringent the standard is, the more effort in innovation the firm has to devote. Only after they have done their innovative part and have conformed with the environmental standards put on their production and emission process, they are permitted to sell their products. It is not a common practice for a government to change its regulation frequently, so it would not be profitable for firms to change the abatement technology they are adopting unnecessarily.

To discuss the main interest of this paper, that is, the effect of greener demand, such as environmental awareness, on firm's decision, while avoiding the political complications and long-term uncertainty problems, we will focus our analysis mainly in the last stage of output decision rather than a much more complicated path of mixing the less frequent long-term R\&D decision and more frequent short-term output decisions. However, put the decision process into a much simplified 2-stage game, we can still analyze the " 1 st stage's long-term" incentive for firms to invest in environmental $R \& D$, that is, $\mathrm{d} \pi_{\mathrm{i}} / \mathrm{d} \theta_{\mathrm{i}}$, because

$$
\frac{d \pi_{i}}{d K_{i}}=\frac{d \pi_{i}}{d \theta_{i}} f^{\prime}\left(K_{i}\right)=v_{i}
$$

and since $v_{i}>0$ and $f^{\prime}<0$, it follows that $\mathrm{d} \pi_{\mathrm{i}} / \mathrm{d} \theta_{\mathrm{i}}<0$. Note that, $\pi_{\mathrm{i}}$ here would be a long-term expected present value of profits, which are very likely to be different from short term profit discussed in our model.

We are considering the case of environmental awareness, which is one of the important social-political factors that promote greener environment, in such case consumers would rather purchase more greener products to encourage an environmental-friendly production. As mentioned in Farzin[6], with the possibility of free-riding problem and the inability for firms to coordinate their emissions reductions, it is necessary for the regulator to set a mandatory emission standard to advance their collective interest, because the firm's voluntary abatement level is likely to be less than the socially desirable level. Socially desirable level might not be the Pareto optimal level if the society have a politically aggressive green party, and they have convincingly persuaded people to demand excessively cleaner environment than economically efficient.

Taking the mandatory environmental standard, the abatement technology, and the other firm's output levels as given, each firm chooses y to maximize

$$
\pi_{i}\left(y_{i}, \alpha\right)=y_{i} P(Y, \alpha)-\theta_{i} \alpha y_{i}-C\left(y_{i}\right)
$$

We will get the optimal output level, $y_{i}^{*}(\alpha)$, from the first order condition

$$
P\left(1-\frac{1}{\varepsilon}\right)-\theta_{i} \alpha-C^{\prime}=0
$$

where $\varepsilon=-(\mathrm{P} / \mathrm{Y})(\mathrm{dY} / \mathrm{dP})>0$. Equation (3) shows that marginal revenue, i.e. $\mathrm{P}(1-1 / \varepsilon)$, equals to marginal cost, i.e. $\theta \alpha+C^{\prime}$. Since $\mathrm{P}(1-1 / \varepsilon) \geq 0$, it follows that $\varepsilon \geq 1$.

The second order condition is

$$
P_{y}\left(1-\frac{1}{\varepsilon}\right) n+p\left(\frac{\varepsilon_{Y}}{\varepsilon^{2}}\right) n-C^{\prime \prime}<0
$$

Differentiating equation (3) with respect to $\alpha$, we have

$$
\left[P_{Y}\left(1-\frac{1}{\varepsilon}\right)+\frac{P}{\varepsilon^{2}} \varepsilon_{Y}\right] \cdot Y_{\alpha}+P_{\alpha}\left(1-\frac{1}{\varepsilon}\right)+\frac{P}{\varepsilon^{2}} \varepsilon_{\alpha}-\theta_{i}-C^{\prime \prime} \frac{d y_{i}}{d \alpha}=0(5)
$$

Since $\mathrm{Y}=n y_{i}$, we have the following

$$
\frac{d Y}{d \alpha}=n \frac{d y_{i}}{d \alpha}+y_{i} \frac{d n}{d \alpha}
$$

Under free entry condition, a competitive firm at the margin would have zero profit, that is, number of firms in the industry is determined by

$$
\pi_{i}\left(y_{i}, n, \alpha\right)=y_{i} P(Y, \alpha)-\theta \alpha y_{i}-C\left(y_{i}\right)=0
$$

Differentiating equation (7) with respect to $\alpha$, we have

$$
\frac{d n}{d \alpha}=\frac{n \varepsilon\left(P_{\alpha}-\theta_{i}\right)}{P}
$$

If consumers care very much about the environment, that is, if firms' effort to reduce the pollution in their production process makes the product more valuable, then the demand effect, i.e. $\mathrm{P}_{\alpha}$, is positive.If $\mathrm{P}_{\alpha}-\theta>0$, then equation (8) shows that a stricter emission standard would increase the number of firm. That is, when the industry increases its abatement level, if the value increased from the demand effect exceeds the abatement costs, the number of firms will increase.

Substituting equation (6) and equation (8) into equation (5) yields

$$
\frac{d y_{i}}{d \alpha}=-\frac{(1-1 / \varepsilon) P_{\alpha}+\varepsilon_{\alpha}\left(P / \varepsilon^{2}\right)-\theta_{i}}{n P_{y}(1-1 / \varepsilon)+\left(n P \varepsilon_{Y} / \varepsilon^{2}\right)-C^{\prime \prime}}
$$


From equation (9), and because of the second order condition, we get

$$
\frac{d y_{i}}{d \alpha} \geq 0 \text { iff } \frac{d(M R)}{d \alpha}-\theta=(1-1 / \varepsilon) P_{\alpha}+\varepsilon_{\alpha}\left(P / \mathcal{E}^{2}\right)-\theta \geq 0(10)
$$

which means if and only if marginal revenue is greater than the marginal cost while tightening up the environmental standard, the firm will be induced to increase its production. In other word, if the government kept demanding more stringent standard for abatement requirement, i.e. $\alpha$ is increasing, if the elasticity of demand is greater than one, and if there exists prevailing environmental awareness so that $P_{\alpha}$ and $\varepsilon_{\alpha}$ both are positive, then the firm will produce more if the demand effect is large enough to cover the cost of compliance.

Since innovation investment decision in our case might take a long and uncertain time to complete and be successful, and most of the cases for environmental abatement innovation are rather a necessity than a profit maximizing decision, we use an indirect way to analyze the incentive for innovation.

The incentive to invest in environmental $R \& D$ can be defined as $k=-(\mathrm{d} \pi / \mathrm{d} \theta)$, which measures how much the profit will increase from improving the abatement technology, that is to reduce the per unit abatement cost. Using the envelope theorem, the incentive of R\&D investment is derived as

$$
k=-\frac{d \pi_{i}^{*}}{d \theta_{i}}=\alpha y_{i}-\frac{P}{\varepsilon} \frac{d y_{i}}{d \theta_{i}}
$$

There are two factors which influence the incentive of R\&D investment in equation (10). The first one is the "direct effect", i.e. $\alpha y_{i}$, which is the savings in abatement costs of developing new abatement technology. The second one is the "induced output effect", i.e. $-(\mathrm{P} / \varepsilon)\left(\mathrm{d} y_{i} / \mathrm{d} \theta_{\mathrm{i}}\right)$, which is derived from lower abatement costs. If the new cost-saving technology increases output for a given abatement target, i.e. $\left(\mathrm{d} y_{i} / \mathrm{d} \theta_{\mathrm{i}}\right)<0$, the incentive to invest will be bigger. However, if $\mathrm{d} y_{i} / \mathrm{d} \theta_{\mathrm{i}}$ is positive, then the "direct effect" may not be sufficient for firm to invest in pollution reduction R\&D. That is, without a positive "induced output effect", the direct effect of cost saving in new abatement technology may not be large enough to warrant $R \& D$ investment.

\section{Concluding Remarks}

The main purpose for this paper is to investigate the effect of market demand for greener product on firm's optimal output strategies. We found that if there's some social-economical factors, such as environmental awareness and grass-root movement aiming toward healthy food and environment, really affect consumer's demand, then it may have some influences on firm's output decision. When the demand effect of such factor is large enough, an increase in mandatory abatement requirement would increase not only the optimal output level but also the number of firms in the industry. When the demand effect of these factors is small, a stricter mandatory requirement would reduce not only the optimal output level but also the number of firms in the industry.

We also checked the factors which have some influences on firms' R\&D strategies. Without the positive "induced output effect", the direct effect of cost saving in new abatement technology may not be large enough to warrant $\mathrm{R} \& \mathrm{D}$ investment. With positive $\varepsilon \mathrm{P}$ and condition on marginal effect of abatement cost, the incentive for R\&D investment is strengthened by a positive "induced output effect".

Even with the presence of factors which promote greener environment, our result may not confirm a strong "Porter's hypothesis". But we do show that with a strong demand effect, and a positive "induced output effect", stringent environmental policy would not only induce firms to innovate on their abatement technology, but also increase their optimal output level.

\section{References}

[1] K. Conrad, "Price Competition and Product Differentiation When Consumers Care for the Environment," Environmental and Resource Economics, vol. 31, issue 1, 2005, pp.1-19.

[2] P. Cooke and D. Wills, "Small Firms, Social Capital and the Enhancement of Business Performance. Through Innovation Programmes," Small Business Economics, vol. 13, issue 3, 1999, pp.219-234.

[3] S. Davenport, "Exploring the Role of Proximity in SME Knowledge-Acquisition," Research Policy, vol. 34, issue 5, 2005, pp.683-701.

[4] T. J. Dean, R. L. Brown, and V. Stango, "Environmental Regulation as a Barrier to the Formation of Small Manufacturing Establishments: A Longitudinal Examination," J. of Environmental Economics and Management, vol. 40, issue 1, 2000, pp.56-75.

[5] V. Denicolo, "Pollution-Reducing Innovations under Taxes or Permits," Oxford Economic Papers, Oxford University Press, vol. 51, issue 1, 1999, pp.184-99.

[6] Y. H. Farzin, "The Effects of Emissions Standards on Industry," J. of Regulatory Economics,vol. 24, issue 3, 2003, pp.315-327.

[7] K. Hoffmana, M. Parejoa, J. Bessant, and L. Perrena, "Small Firms, R\&D, Technology and Innovation in the UK: a Literature Review," Technovation, vol. 18, issue 1, 1998, pp.39-55.

[8] D. Keeble, "Small Firms, Innovation and Regional Development in Britain in the 1990s,"Regional Studies, vol. 31, issue 3, 1997, pp.281-293.

[9] Jean-JacquesLaffontand JeanTirole, "Pollution permits and environmental innovation," Journal of Public Economics, Elsevier, vol. 62, issue 1-2, 1996, pp.127-140.

[10] L. A. Lefebvre and E. Lefebvre, " Competitive positioning and innovative efforts in SMEs," Small Business Economics, vol. 5, issue 4, 1993, pp.297-305. 
[11] R. D.Mohr, "Technical Change, External Economies, and the Porter Hypothesis," J. of Environmental Economics and Management, vol. 43, 2002, pp.158-168.

[12] J. P. Montero, "Permits, Standards, and Technology Innovation," J. of Environmental Economics and Management, vol. 44, issue 1, 2002, pp.23-44.

[13] J. L. Moraga-Gonzalez and N. Padrón-Fumero, "Environmental Policy in a Green Market," Environmental and Resource Economics, vol. 22, issue 3, 2002, pp.419-447.

[14] L. K. Mytelka, "Local Systems of Innovation in a Globalized World Economy," Industry \& Innovation, vol. 7, issue 1,2000, pp.15-32.

[15] G. Noci and R. Verganti, "Managing 'Green' Product Inno- vation in Small Firms," R\&D Management, vol. 29, issue 1,1999, pp.3-15.

[16] T. Ono and Y. Maeda, "On the index of environmental awareness," Environmental Economics and Policy Studies, vol. 5,2002, pp.167-178.

[17] M. E. Porter, "America's Green Strategy," Scientific American,vol. 264,1991, pp.168.

[18] M. E. Porter and C. van der Linde, "Green and Competitive: Breaking the Stalemate," Harvard Business Review, September-October issue, 1995.

[19] M. E. Porter and C. van der Linde, "Toward a New Conception of the Environment-Competitiveness Relationship," J. of Economic Perspectives, vol. 9, Issue 4, 1995, pp. 97-118. 